\title{
Research Article \\ EXTENT OF ADOPTION OF PRODUCTION TECHNOLOGIES OF HYVS OF GLUTINOUS RICE DEVELOPED AT RARS, AAU, TITABAR, ASSAM
}

\author{
HEJBINA M HUSSAIN*, BORDOLOI N. AND DUTTA J.K. \\ Department of Extension Education, Assam Agricultural University, Jorhat, Assam 785013 \\ *Corresponding Author: Email-mehzabinhezbina02@gmail.com
}

\author{
Received: February 03, 2018; Revised: February 15, 2018; Accepted: February 16, 2018; Published: February 28, 2018
}

\begin{abstract}
The present study was carried out in the Jorhat district of Assam to assess the extent of adoption of HYVs of glutinous rice and its package of practices recommended by Assam Agricultural University. A multistage purposive cum random sampling technique was followed and statistical method such as frequency, percentage, mean, and standard deviation was used for analyzing the data. Data were collected through personal interview technique administering a structured schedule. A total of 120 respondents constituted the sample of the study. Majority $(65.83 \%)$ of the respondents had medium level of adoption of HYVs of glutinous rice. Among all the 14 practices recommended by AAU, only 6 of them such as harvesting, spacing, number of seedlings per hill, sowing time, variety and seed selection had highest number of full adopters. However, "line transplanting" and "irrigation" had the highest number of "non adopters" i.e. $81.67 \%$ and $69.17 \%$ respectively. The study implies that majority of the respondents were partial adopters in case of selected recommended package of practices and their extent of adoption increases with increase in "annual income" and "economic motivation". This suggests that the extension agencies should continue their efforts in accelerating the adoption of recommended cultivation practices for HYVs of glutinous rice.
\end{abstract}

Key words- Glutinous rice, adoption; package of practices; Assam

Citation: Hejbina M. Hussain, et al., (2018) Extent of Adoption of Production Technologies of HYVs of Glutinous Rice Developed at RARS, AAU, Titabar, Assam. International Journal of Agriculture Sciences, ISSN: 0975-3710 \& E-ISSN: 0975-9107, Volume 10, Issue 4, pp.-5149-5152.

Copyright: Copyright@2018 Hejbina M. Hussain, et al., This is an open-access article distributed under the terms of the Creative Commons Attribution License, which permits unrestricted use, distribution and reproduction in any medium, provided the original author and source are credited.

Academic Editor / Reviewer: Saini V, Suleyman Cylek

\section{Introduction}

Rice is life for majority of the world's population and is deeply embedded in the cultural heritage of the societies. Rice based production systems and their associated post harvest operations employ nearly a billion people in rural areas in the developing countries. Rice accounted for nearly 18 percent of the national GDP and provided about 70 percent of an average citizen's total calorie intake. Rice area totaled about 10 million ha, and accounted for 75 percent of the total cropped area and 93 percent of total area under cereals (IRRI, 2008)[1]. Small scale farmers in low income and developing countries grow about four-fifths of the world's rice production. It has shaped the culture, diets and economic of thousand of millions of people. Considering its important position, the United Nations designated the year 2004 as the "International Year of Rice" to focus the world's attention on the role that rice can play in providing food security and poverty alleviation (Twenty-four FAO Regional Conference for Europe)[2].

Assam is recognized as a centre of origin of rice with a rich source of genetic diversity. Variations in ecological conditions, ethnic diversity, diverse cultural practices and different quality preferences are contributing to different types of rice available in this region. Among the different types of rice, glutinous rice is an important class, categorized as waxy and soft rice because of its cooking consistency. Glutinous rice, also known as sticky rice occupies a special place in the Assamese culture. It is popularly known as bora saul in Assam. It is used in many recipes throughout the state (Anonymous, 2008-09)[3]. Bora Saul forms the core component of Assamese sweets, snacks, and breakfast. They are widely used in every kind of traditional sweets of Assam which are very different from traditional sweets of India of which basic component is milk.

Bora rice is Assam's valuable biological wealth with huge commercial value.
Though this potential has been increasingly recognized in recent years, the desired results have not come through as yet. (Borthakur et al, 2015)[4]. As the Indian market is opening up and communication too is improving, the scope of benefiting from such wealth is also increasing. The consumers globally are ready to pay more for anything special and organic. This study was designed to cover the extent of adoption of high yielding varieties of glutinous rice and their associated practices in Jorhat district. The particularity of the study was that it is confined to measure the extent of adoption of those high yielding varieties which were developed by R.A.R.S, Titabar and had got recommendation. In order to know the present level of adoption the study was carried out with the objective: To study the extent of adoption of high yielding varieties of Glutinous rice developed at RARS, Titabar in Assam.
Methodology
The present study was conducted in twelve villages under Jorhat district of Assam, because Regional Agricultural Research Station is located in the Jorhat district and also the three high yielding varieties of glutinous rice namely Aghoni, Bhogali and Rongilee has been developed from Regional Agricultural Research Station of Jorhat. A multistage purposive cum random sampling design was followed for selection of sub-divisions, Agricultural
Development Officers (ADO) circles, villages and respondents. There were 12 randomly selected villages. From each of the village, 10 numbers of farmers were selected randomly. Thus, there were in total 120 respondents who constituted the final sample of the study.
The dependent variable of the study was extent of adoption of high yielding varieties of glutinous rice cultivation practices by the farmers, which has been 
conceived as the adoption of the recommended cultivation practices against three response categories, viz., full adoption, partial adoption and no adoption. If a farmer was found to adopt a given practice as per recommendation, it was considered as 'full adoption' and was assigned a score of 2. A deviation from the recommended practice was considered as 'partial adoption' which was assigned a score of 1. Farmers who did not follow the recommended practice at all were considered as 'no adoption' and were assigned a score of 0 . The measurement procedure for measuring extent of adoption was followed in the light of the procedure following by Saikia (2016)[5]. The extent of adoption was calculated for 14 selected cultivation practices as recommended by Assam Agricultural University, Department of Agriculture, Govt. of Assam and consulting with concerned AAU experts. The total score obtained by a respondent was calculated by adding the adoption scores for all the practices followed by that respondent. On the basis of the mean $(X)$ and standard Deviation (S.D.) of obtained scores, respondents were classified into three categories as follows:

\begin{tabular}{|c|c|}
\hline Category & Range \\
\hline Low & Below( $(\mathbb{X}-$ S.D. $)$ \\
\hline Medium & Between $(\mathbb{X}$-S.D) and([X+S.D.) \\
\hline High & Above( $(\mathbf{X}+$ S.D. $)$ \\
\hline
\end{tabular}

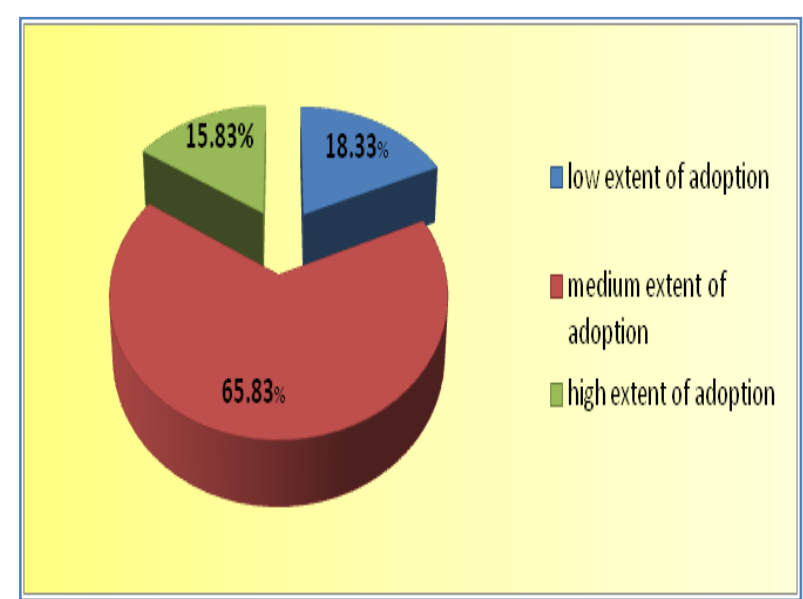

Fig-1.1 Distribution of Respondents According To Overall Extent of Adoption of HYVs of Glutinous Rice and Its Recommended Package of Practice

\section{Results and Discussion}

\section{Extent of adoption of HYVs of Glutinous rice by the farmers:}

[Table-1] reveals that in respect of extent of adoption of HYVs of glutinous rice, majority (65.83\%) of the respondents had medium level of extent of adoption, followed by 18.33 per cent of the respondents having low level of extent of adoption and 15.83 percent had high level of extent of adoption. The mean and standard deviation (SD) calculated were 37.18 and 6.97 respectively. Similar findings were also reported by several workers (Borthakuret al, 2015; Singh and Varshney, 2010; and Borua and Brahma., 2012)[6].

Table-1 Distribution of respondents according to overall extent of adoption of recommended package of practice of high yielding varieties of glutinous rice $(N=120)$

\begin{tabular}{|c|c|c|c|c|c|}
\hline Category & Score Range & Frequency & $\begin{array}{c}\text { Percentage } \\
(\%)\end{array}$ & Mean & S.D \\
\hline Low extent of adoption & $<30.17$ & 22 & 18.33 & & \\
\cline { 1 - 5 } Medium extent of adoption & 30.17 to 44.13 & 79 & 65.83 & \multirow{3}{*}{37.18} & 6.97 \\
\hline High extent of adoption & $>44.13$ & 19 & 15.84 & & \\
\cline { 1 - 4 } Total & & 120 & 100.00 & & \\
\hline
\end{tabular}

Practice wise extent of adoption of HYVs glutinous rice cultivation practices:

It is observed in [Table-2] that cent percent respondents (100.00\%) fully adopted the recommended varieties. The reason for full adoption of the HYV varieties might be because of awareness about the varieties, good yield and advantageous characteristics of the varieties.

It is seen that $59.17 \%$ of the respondents fully adopted the seed selection procedure, $39.17 \%$ partially adopted the seed selection procedure and $1.67 \%$ did not adopt the seed selection procedure. The reason behind full adoption of this practice was because of less complexity involved in the practice, awareness about the practice, insignificant expenditure involved, also because of more or less similarity with the conventional or traditional practice etc.

Table-2 Distribution of respondents according to their practice wise extent of adoption of HYVs glutinous rice cultivation practices.

\begin{tabular}{|c|c|c|c|c|}
\hline SI. No & Practices & $\begin{array}{c}\text { FA } \\
\text { Frequency (\%) }\end{array}$ & \begin{tabular}{|c|} 
PA \\
Frequency (\%)
\end{tabular} & $\begin{array}{c}\text { NA } \\
\text { Frequency (\%) }\end{array}$ \\
\hline \multirow[t]{3}{*}{1} & a) Variety (HYV) & $120(100.00)$ & $0(0.00)$ & $0(0.00)$ \\
\hline & b) Seed selection & $71(59.17)$ & $47(39.17)$ & $2(1.67)$ \\
\hline & c) Seed treatment & $32(26.67)$ & $58(48.33)$ & $30(25.00)$ \\
\hline \multirow[t]{4}{*}{2} & Nursery bed preparation & & & \\
\hline & a)size of the nursery bed & $54(45.00)$ & $66(55.00)$ & $0(0.00)$ \\
\hline & b)quantity of seed & $27(22.50)$ & $92(76.67)$ & $1(0.83)$ \\
\hline & $\begin{array}{l}\text { c)recommended } \\
\text { fertilizer application }\end{array}$ & $33(27.50)$ & $19(15.83)$ & $68(56.67)$ \\
\hline 3 & Sowing time & $111(92.50)$ & $7(5.83)$ & $2(1.67)$ \\
\hline 4 & Line transplanting & $9(7.50)$ & $13(10.83)$ & $98(81.67)$ \\
\hline 5 & $\begin{array}{l}\text { Treatment of seedlings } \\
\text { (in seed bed or } \\
\text { afteruprooting }\end{array}$ & $38(31.67)$ & $30(25.00)$ & $52(43.33)$ \\
\hline \multirow[t]{2}{*}{6} & Transplanting of seedlings & & & \\
\hline & Number of seedlings per hill & $67(55.83)$ & $53(44.17)$ & $0(0.00)$ \\
\hline 7 & Field Preparation & $0(0.00)$ & $120(100.00)$ & $0(0.00)$ \\
\hline 8 & $\begin{array}{l}\text { Recommended fertilizer } \\
\text { Application }\end{array}$ & $49(40.83)$ & $65(54.17)$ & $6(5.00)$ \\
\hline \multirow[t]{3}{*}{9} & Spacing & & & \\
\hline & Plant to plant & $66(55.00)$ & $54(45.00)$ & $0(0.00)$ \\
\hline & Row to row & $66(55.00)$ & $54(45.00)$ & $0(0.00)$ \\
\hline 10 & Gap filling & $16(13.33)$ & $54(45.00)$ & $50(41.67)$ \\
\hline \multirow[t]{4}{*}{11} & Split application of Urea & & & \\
\hline & No. of split urea & $65(54.17)$ & $46(38.33)$ & $9(7.50)$ \\
\hline & Time of application & $60(50.00)$ & $51(42.50)$ & $9(7.50)$ \\
\hline & Amount & $50(41.67)$ & $60(50.00)$ & $10(8.33)$ \\
\hline \multirow[t]{7}{*}{12} & Plant protection measures & & & \\
\hline & Insect/pest & & & \\
\hline & Nursery bed & $8(6.67)$ & $106(88.33)$ & $6(5.00)$ \\
\hline & Main Field & $6(5.00)$ & 111(92.50) & $3(2.50)$ \\
\hline & Diseases & & & \\
\hline & Nursery bed & $18(15.00)$ & $82(68.33)$ & $20(16.67)$ \\
\hline & Main field & $11(9.17)$ & $100(83.33)$ & $9(7.50)$ \\
\hline \multirow[t]{4}{*}{13} & |rrigation & & & \\
\hline & Time of Irrigation & $17(14.16)$ & $25(20.83)$ & $78(65.00)$ \\
\hline & Method of irrigation & $10(8.33)$ & $22(18.33)$ & $88(73.33)$ \\
\hline & No. of irrigation & $10(8.33)$ & $27(22.50)$ & $83(69.17)$ \\
\hline 14 & Harvesting & 112(93.33) & $8(6.67)$ & $0(0.00)$ \\
\hline
\end{tabular}

The data presented in the Table above, 48.33 percent of the respondents partially adopted and $26.67 \%$ respondents fully adopted the seed treatment procedure. About 25 percent did not adopt the procedure at all. It is assumed that respondents showing partial or no adoption was probably because they were not aware of the correct doses of seed treatment and the benefits of this practice against seed borne diseases.

About 55 percent of the respondents followed partial adoption relating to the size of the nursery bed, 45 per cent of them fully adopted this practice and followed the recommended size of the seed bed i.e. $10 \mathrm{~m}$ length $\times 1.25 \mathrm{~m}$ breadth with $30 \mathrm{~cm}$ gap in between the beds.

Seed rate was also partially adopted by majority $(76.67 \%)$ of the respondents followed by 22.50 per cent of full adopters and 0.83 percent of non adopters. The reason behind this may be that most farmers tend to follow approximate values as they might think that accurate rates would not make much of a difference.

In case of application of manures and fertilizers in nursery beds, it was found that only 27.50 per cent fully adopted the recommended doses, followed by 15.83 per cent of the partial adopters and highest number of non adopters (56.67\%). It is 
assumed that majority of the respondents did not use recommended chemicals for pest and disease control in nursery bed due to lack of skill in identifying pest and diseases, high cost of labour, high cost of inputs and non-availability of trained labours.

Majority of the respondents (92.50\%) followed recommended sowing time. Among the respondents, about 5.83 percent were partial adopters and 1.67 percent was non adopters. The reason for full adoption of this practice was due to awareness about it.

Majority (81.67\%) of the respondents did not adopt line transplanting. Only 10.85 per cent partially adopted the practice while only 7.50 per cent fully adopted this practice. The reason for non adoption was that, this practice requires more labour and requires skills. According to the farmers, it was not suitable when no irrigation source was available.

Majority of the respondents (43.33\%) were non adopters, followed by 31.67 per cent of full adopters and 25.00 percent of partial adopters.

Majority did not treat the seedlings with Carbofuran. Only 32.67 percent fully adopted the treatment of seedlings with carbofuran or chloropyriphos as a protective measure against stem borer, gall midge etc. Rest of the respondents partially adopted.

About 55.83 percent of the respondents fully adopted this practice and the remaining 44.17 percent partially adopted the practice. The reason behind full adoption was due to its similarity with the traditional method and also because of farmer's awareness about the practice. The reason behind partial adoption was due to their poor knowledge about the practice. The table reveals that 100 percent respondents partially adopted this practice. This was because most of the farmers prefer ploughing only. They do not go for laddering and harrowing along with ploughing, which was a recommended practice.

It is seen that majority $(54.17 \%)$ of the respondents partially adopted the practice of recommended fertilizer followed by 40.83 percent of total respondents who fully adopted this practice. The reason for partial adoption was due to unawareness about the practice.

Majority $(55.00 \%)$ fully adopted the plant to plant spacing as per recommendation. The remaining were partial adopters. Also majority $(55.00 \%)$ of respondents fully adopted the row to row spacing and the remaining were partial adopters.

Majority of the respondents (45.00\%) partially adopted the practice of gap filling, followed by no adoption with 41.67 percent and partial adoption with $13.33 \%$. The [Table-2] reveals that majority $(54.17 \%)$ fully adopted this practice. The remaining 38.333 percent of the respondents partially adopted the practice followed by 7.50 percent respondents being no adopters.

Again majority (50.00\%) of the respondents followed this practice fully. About

42.50 percent deviated from the practice while 7.50 percent did not adopt the practice. It is assumed that the reasons behind partial and no adoption of the practice were due to poor training exposure, unawareness of the practice etc, time of application untimely supply of inputs,

As seen in the [Table-2], majority of the respondents (50.00\%) partially followed the recommended dosage of split application of urea, followed by 41.67 percent who followed the dosage fully. About 8.33 percent of them did not follow the doses at all.

The [Table-2] shows that the majority of the respondents (88.33\%) partially adopted the recommended chemicals, followed by 6.67 per cent of the total respondents who fully adopted the practice and 5 percent did not adopt at all in case of pest attack in nursery bed.

Again, in case of pest attack in main field the majority of the respondents $(92.50 \%)$ partially adopted the practice followed by 5 per cent and 2.00 per cent of the total respondents who were full adopters and non adopters of the practice respectively. In case of disease in nursery bed, 68.33 percent partially followed the practice of using the recommended chemicals, followed by 16.67 percent non adopters and 15 percent full adopters. Similarly, in case of main field, the recommended chemicals were partially followed by 83.33 percent respondents, followed by 9.17 percent of full adopters and 7.50 percent of non adopters of the practice. Both in case of pest and diseases, majority of the respondents partially adopted the recommended quantity of chemicals was due to the respondents' unfelt needs about the plant protection measures. This means that the farmers were more experienced in case of plant protection measures. And as it was completely need based, majority showed partial adoption. No adoption might be a way to decrease the cost of cultivation and unawareness about the practice, poor extension contact and mass media exposure etc.

From the table it is seen that majority of the respondents $(65.00 \%)$ did not follow the irrigation time which was recommended, followed by 20.80 percent of partial adopters and only 14.16 percent of full adopters of this practice. Again majority $(73.33 \%)$ of the respondents did not follow the recommended method of irrigation, followed by 18.33 percent of partial adopters and remaining 8.33 percent followed the practice fully. In case of number of irrigations, about 93.33 percent followed it fully and remaining 6.67 percent followed it partially.

Majority $(93.33 \%)$ of the respondents harvest the produce well in time and only 6.67 percent of them faced difficulties in harvesting the produce in time; therefore they fell under partial adopters. The reason might be due to natural calamities like flood, or unavailability of labours etc.

\section{Conclusion}

The study revealed that majority of the sampled respondents had medium level of adoption. It was seen that maximum extent of adoption was found in case of varieties followed by harvesting. Whereas least extent of adoption was observed in case of line transplanting followed by irrigation. Based on the findings, it can be suggested that to enhance adoption, training programmers should target the young to medium aged small farmers with medium to higher level of extension contact. The small glutinous rice grower's Should be trained in recommended rice cultivation technology to increase the adoption rate and the problems may be solved through extension activities like exposure visits, awareness about banking schemes and government policies.

Application of Research: The study will be helpful in measuring the level of adoption of high yielding varieties of glutinous rice and their associated practices in Jorhat district of Assam.

\section{Abbreviations: FA-Full Adoption, PA-Partial Adoption, NA-No Adoption}

Acknowledgement: The author honestly acknowledges Dr Nagen Bordolo Teaching staff of Department of Extension Education and Department of Statistics, Assam Agricultural University, Jorhat, 785013, Assam, India for extending their full cooperation, help, care during the research.

Name of the Research Guide: Dr Nagen Bordoloi

University: Assam Agricultural University, Jorhat, 785013, Assam

Research Project Name or Number: NIL

Author's contributions: All author equally contributed.

Author statement: all author read, reviewed, agree and approved the final manuscript

\section{Conflict of Interest: None declared}

Ethical approval: This article does not contain any studies with human participants or animals performed by any of the authors

\section{References}

[1] International Rice Research Institute. (2008) Facts about Cooperation: Bangladesh and IRRI. Available at http://www.irri.org/media/facts/pdfs/BANGLADESH.pdf accessedon12.08.2008

[2] Twenty Fourth FAO Regional conference for Europe, Montpellier, France, Food and Agriculture Organization for United Nations. www.fao.org/docrep/meeting/008/J2673/J267coo.htm 
[3] Anonymous (2008-09) Status Paper on Rice in Assam. www.rkmp.co.in.

[4] Borthakur S., Mishra P., Talukdar R.K and Bortamuly D (2015) Indian Res. J. Ext. Edu., 15 (2).

[5] Saikia P. (2016) A study on adoption of improved practices of Boro paddy cultivation by the farmers of Biswanath sub-division, Sonitpur, Assam. Unpublished M.Sc.(Agri.) Thesis, Assam Agricultural University

[6] Boruah S. and Brahma A.K. (2012) J. Acad. Indus. Res., 1(7). 